\title{
Optimal Discount Rates for Government Projects
}

\author{
Sangkyun Park \\ Office of Management and Budget, 725 17th Street NW \#9025, Washington, WA 20503, USA \\ Correspondence should be addressed to Sangkyun Park, sangkyun_park@omb.eop.gov
}

Received 19 April 2012; Accepted 16 May 2012

Academic Editors: E. L. Khalil, N. Vestergaard, and E. Yeldan

Copyright ( 12012 Sangkyun Park. This is an open access article distributed under the Creative Commons Attribution License, which permits unrestricted use, distribution, and reproduction in any medium, provided the original work is properly cited.

\begin{abstract}
Project selection based on the net present value can be optimal only if the discount rate is optimal. The optimal discount rate for a government project can be a risk-free rate, a comparable market rate (market interest rate corresponding to the risk of cash flows to the government), or an adjusted market rate, depending on circumstances. This paper clarifies the conditions for each case. Provided that the optimal discount rate is the comparable market rate, it varies across intervention methods and changes with the subsidy rate.
\end{abstract}

\section{Introduction}

The government should allocate its budget to maximize social welfare. When the net present value (NPV) is used as the basis of project choice, the discount rate critically influences budget allocation. Yet there is no consensus on the optimal discount rate that would maximize social welfare.

An old debate is whether the discount rate for a government project should reflect the risk premium (compensation for uncertainty) that is normally demanded in the market, in addition to the time preference of individuals. Another line of research focuses on determining the social discount rate that reflects the society time preference best. Both issues have attracted considerable attention in recent years.

In the USA, the Federal Credit Reform Act of 1990 has explicitly incorporated discounting into the federal budget, although it is limited to credit programs. Under the act, expected cash flows from government credit programs are discounted by Treasury rates of comparable maturities. Assuming that the Treasury rate approximates the riskfree rate, the government discount rate does not contain the risk premium in this case. The Emergency Economic Stabilization Act of 2008, however, mandates that cash flows from the Troubled Asset Relief Program be discounted by market risk-adjusted discount rates (Treasury rates plus risk premiums that would be demanded by private investors), rekindling the old debate in the policy arena.
Increased concerns about climate changes and needs for environmental regulation have heightened the importance of the social discount rate. For environmental policies, which typically have large effects in a very distant future, costbenefit analyses are extremely sensitive to the discount rate. Important issues arising from the long time horizon include uncertainty about the discount rate itself, intergenerational inequality in consumption, and rationales for applying a lower discount rate to a farther future.

The focus of this paper is on the market risk premium. Research in the social discount rate has been flourishing, although the conclusion is yet to be reached. (See, e.g., Gollier [1], Groom et al. [2], Moore et al. [3], and Weitzman [4], and also see Zeckhauser and Viscusi [5] for the discussion of critical issues.) These studies dealing with public goods focus on the intertemporal time preference, as opposed to the cross-sectional variation of returns across projects. For public goods with a long time horizon and a relatively stable return, the risk premium varying across projects may be of secondary importance. Given that governments around the world intervene in many private-market activities including credit extension, however, the market risk premium is an important public policy issue for many government programs.

Some early studies (e.g., Arrow and Lind [6], Samuelson [7], and Vickrey [8]) have advocated the risk-free rate as the appropriate discount rate for government projects. According to them, the government should ignore uncertainty in 
evaluating public investments and discount the costs and benefits of government projects by the risk-free rate. The government invests in a great number of diverse projects, and it is able to pool risks to a much greater extent than private investors. In addition, the government distributes the risk associated with any investment among a large number of people. Thus, when the risk associated with a public investment is publicly borne, the total cost of risk bearing is insignificant.

Many others (e.g., Hirshleifer [9], Diamond [10], Sandmo [11], Bazelon and Smetters [12], and Lucas and Phaup [13]) argue that the costs and benefits of government projects should be discounted by market rates that private investors use to discount comparable projects (comparable market rates), where comparable projects are those with proportionately the same time and state distributions of cash flows. Since market interest rates fully reflect individuals' time and risk preferences, applying different discount rates for government projects would lead to the selection of inferior projects and decrease social welfare.

To apply either view to public policies appropriately, one needs to identify precisely the conditions under which each case holds. The efforts to analyze this issue rigorously have stalled after the active debates of the 60s and the 70s. More recent works discuss the issue at intuitive and practical levels.

This paper uses a state-preference model to achieve two objectives. One is to clarify the conditions under which each class of discount rate is optimal for government projects. The state-preference model, which is a basis of modern finance including the Capital Asset Pricing Model, is the most fundamental tool to price risks. The model is also general enough to accommodate other models including that of Arrow and Lind [6]. The conditions for each case become much clearer when both views are rigorously analyzed within the same framework.

A more novel objective is to derive optimal discount rates for different types of government programs under the assumption that comparable market rates are optimal for government projects. If the government should discount cash flows with comparable market rates, it is important to derive the comparable market rate for each program rigorously. Right market rates should be used to improve resource allocation, and to be practical, comparable market rates should be easy to obtain.

The state-preference model shows that the optimal discount rate for a government project can be a risk-free rate, a comparable market rate, or an adjusted market rate, depending on circumstances. The key factors determining the optimal discount rate are the dependence of the project return on the private state, the extent to which the project risk is shared among individuals, diversification abilities of the private sector and the government, and risk aversion in relation to wealth. Conditions for each case are summarized in Propositions 1, 2, and 3. A risk-free rate may be appropriate for small research projects, while a comparable market rate may be more appropriate for projects involving widespread market activities, such as mortgage lending, that are tied to the performance of the overall economy.
At the individual level, it is hard to diversify risks of certain activities, such as investment in human capital. For projects involving those activities, the optimal discount rate may be an adjusted market rate.

Provided that the optimal discount rate is the comparable market rate, the optimal social outcome is attained when the government uses the comparable market rate reflecting the risk of its own cash flows, as opposed the cash flows from the underlying project or the ultimate cash flows to taxpayers. In other words, the final outcome is optimal when every agent including the government properly prices the nondiversifiable risk that it faces.

Another key finding is that for government programs involving the same underlying project, the comparable market rate differs across intervention methods (such as direct investment, loans, and loan guarantees) and changes with the subsidy rate. The reason is that the risk profile (state contingency) of cash flows belonging to the government is determined by the intervention method and the subsidy rate. Consider a corporation undertaking a project (underlying project). The risk profile of cash flows from the underlying project differs across claimants, such as shareholders and bondholders (analogous to intervention methods). The risk profile also depends on contract terms (analogous to the subsidy rate).

The rest of the paper is organized as follows. The next section formulates the basic framework of the analysis. Section 3 examines the appropriateness of a risk-free rate, a comparable market rate, and an adjusted market rate as the optimal discount rate for a government project and articulates the conditions for each case. Section 4 shows that the optimal discount rate varies across intervention methods and changes with the subsidy rate. Section 5 concludes.

\section{Market Discount Rates}

The basic model is based on state-preference theory. (See Hirshleifer [14] for detailed illustrations of many features of this model.) Since it is a well-established model, algebraic details are relegated to Appendices.

2.1. Structure of the Economy. The economy has two periods: 0 and 1 . While everything is certain in period 0 , period 1 can turn out to be either good or bad. Individuals have the identical preference and endowment. In period 0 , each individual is endowed with one unit of commodity that can be divided between immediate consumption and the purchase of future commodities (investment). The market for future commodities is complete and competitive.

2.2. Utility Maximization. Individuals maximize utility by choosing the optimal levels of consumption and investment in period 0 . For simplicity, the utility function is assumed to be time separable and state independent. Individuals are risk averse, and the utility function exhibits constant relative risk aversion. 
Under these assumptions, the expected utility is

$$
E(U)=v\left(c_{0}\right)+\frac{\pi_{G} v\left(c_{1 G}\right)}{1+\rho}+\frac{\pi_{B} v\left(c_{1 B}\right)}{1+\rho},
$$

where $v$ is a cardinal utility function exhibiting constant relative risk aversion, $c_{0}$ is period- 0 consumption, $c_{1 s}$ is period-1 consumption if state $s(s=G, B$, where $G$ and $B$ resp. denote the good state and the bad state) is realized, $\pi_{s}$ is the probability that state $s$ is realized, and $\rho$ is the time discount rate. (Refer to Notations attached at the end of the paper.)

The budget constraint is

$$
c_{0}+p_{1 G} c_{1 G}+p_{1 B} c_{1 B} \leq 1
$$

where $p_{1 s}$ is the per-unit price of commodity to be delivered in period 1 if state $s$ is realized. (See Appendix E for firstorder conditions and optimization.)

2.3. Production Technology and Discount Rates. For simplicity, I assume constant-return-to-scale technology. There are two investment opportunities: $I_{G}$ and $I_{B}$. A one-unit investment in $I_{G}$ yields $\alpha$ units in the good state and 0 in the bad state, while a one-unit investment in $I_{B}$ yields $\beta$ units in the bad state and 0 in the good state $\left(\pi_{G} \alpha>\pi_{B} \beta\right)$. Since the supply is perfectly elastic,

$$
p_{1 G}=\frac{1}{\alpha}, \quad p_{1 B}=\frac{1}{\beta} .
$$

The price of a package consisting of $q_{1 G}$ units of the goodstate commodity and $q_{1 B}$ units of the bad-state commodity is the sum of the price of each commodity times its quantity $\left(p_{1 G} q_{1 G}+p_{1 B} q_{1 B}\right)$. Since the present value of this package must be equal to its price, the discount factor is the expected number of period- 1 commodities $\left(E\left(q_{1}\right)=\pi_{G} q_{1 G}+\pi_{B} q_{1 B}\right)$ divided by the price. Thus, when $E\left(q_{1}\right)=1$, the discount factor is simply the inverse of the price. Uncertainty is eliminated if an individual buys one unit of the good-state commodity and one unit of the bad-state commodity. When $q_{1 G}=1$ and $q_{1 B}=1, E\left(q_{1}\right)=1$ since $\pi_{G}+\pi_{B}=1$. Thus, the risk-free discount factor $\left(R_{f}\right)$ is the inverse of the price of this risk-free package $\left(p_{1 G}+p_{1 B}\right)$. Since the bad-state commodity is more valuable than the good-state commodity, $R_{f}$ is larger than the discount factor for the badstate commodity $\left(R_{B}\right)$ and smaller than that for the goodstate commodity $\left(R_{G}\right)$, and the discount factor for a package of future commodities increases with the share of the goodstate commodity. Appendix A presents algebraic expressions for various prices and discount factors.

\section{Government Projects}

This section considers three cases: government projects face the same uncertainty as private projects; government projects have return distributions that are independent of the private state; the government faces the same uncertainty, but it has a superior ability to diversify across states. The optimal discount rate differs across these cases.
3.1. Government Projects Facing the Same Uncertainty. Suppose that the return on a government project depends on whether period 1 turns out to be good or bad. Ultimately, all resources invested in the government project come out of the individuals' budget and the investment returns are added back to the individuals' budget, regardless of the method of financing. Thus, the social welfare is maximized when the government uses discount rates that would lead to the same investment decisions as those of the private sector. Appendix $\mathrm{B}$ algebraically shows this result under bond financing and tax financing.

Undertaking a project with a negative NPV at the market discount rate but a positive NPV at a lower government discount rate would be like overpaying for a future good. After the overpayment, the budget constraint would be tighter and the maximum attainable utility would be lower. This efficiency loss cannot be eliminated by risk sharing; while the per-capita loss will decrease with the number of individuals, the aggregate loss will be basically unaffected by the number of individuals. (See Appendix E for simulation results.) Likewise, an opportunity to improve social welfare would be missed if the government passed up a project with a positive NPV at the market discount rate but a negative NPV at a higher government discount rate. Thus, if the government faces the same uncertainty, it must discount its cash flows with the market discount rate and undertake positive NPV projects to maximize social welfare.

3.2. Government Projects with Independent Return Distribution. Suppose that a government project yields either a high or a low return in period 1 , independent of the private state. The probability of the high return is the same in both the good and the bad states. Thus, when the high (low) return is realized, both the good-state and the bad-state consumption increase (decrease) by the same amount.

The per-individual utility loss from this uncertainty increases with the gap between the high-return consumption and the low-return consumption. Thus, as the number of individuals sharing the risk increases, the utility loss decreases. Furthermore, the rate of decrease in the utility loss accelerates with the number of individuals sharing the risk if the relative risk aversion is constant or the absolute risk aversion decreases with wealth; individuals do not care much about the risk when the uncertain consumption is a very small fraction of total consumption. Thus, when a sufficiently large number of individuals share the risk of the government project, the utility loss becomes negligible both at the individual level and at the aggregate level. (See Appendix $\mathrm{C}$ for an algebraic presentation and Appendix E for simulation results.)

Once the utility loss from independent risk becomes negligible, the government project is practically risk-free because the return is the same in the good and the bad states. Then, the government undertaking of the project is like purchasing risk-free goods for individuals. Whether the government project makes individuals better off depends on the price paid by the government on behalf of individuals. Paying a price higher (lower) than the fair market price for 
risk-free cash flows would make individuals worse (better) off by effectively reducing (increasing) the total budget, thus, in this case, the appropriate discount rate is the risk-free rate.

3.3. Lower Diversification Costs for the Government. Suppose that it is costlier for individuals to diversify than for the government due to some transactions costs (e.g., costs of hedging human capital or home equity). With the transactions costs, the effective price for individuals is higher than the market price. In this case, the effective budget of individuals increases if the government purchases a future commodity on behalf of individuals at a price that is lower than the individuals' effective price. If the transactions costs are zero for the government, the optimal discount factor for the government is the inverse of the individuals' effective price per expected unit, which is smaller than the market discount factor (inverse of the market price per expected unit). Positive transactions costs for the government increase the optimal discount factor, but it remains to be smaller than the market discount factor as long as transactions costs are lower for the government than for individuals. (See Appendix D for an algebraic presentation.)

3.4. Risk-Free Rates versus Market Rates. The results above can be organized into the following propositions.

Proposition 1. The optimal discount rate for a government project is the risk-free rate if (C11) the project risk is independent of private states (unrelated to nondiversifiable private risks), (C12) the government costlessly distributes the risk among a large number of individuals, (C13) the project size is moderate, and (C14) relative risk aversion is constant (or absolute risk aversion decreases with wealth).

All four conditions must hold. The market rate is the relevant rate when $(\mathrm{C} 11)$ does not hold. (C12) and (C13) are necessary to make the effect of the independent risk negligible at the individual level. If (C14) does not hold, the independent risk still results in a large loss in aggregate utility, even when the utility loss is small at the individual level.

Proposition 2. The optimal discount rate for a government project is the comparable market rate if (C21) the government project faces the same non-diversifiable risks as those faced by private projects, and (C22) the private sector eliminates diversifiable risks completely or to the same extent that the government does.

If (C21) and (C22) hold, the welfare of individuals is determined basically by the market value of project returns. Thus, the government should use the same investment criterion as the one used in the private sector. The comparable market rate, however, is not necessarily higher than the riskfree rate; it is lower than the risk-free rate if the project yields much more in the bad state, compared with typical private projects. Given that the government pursues many objectives other than profits, the risk profiles of many government projects may differ from that of an average private project.
For antipoverty programs, for example, both costs and benefits may be higher in the bad state.

Proposition 3. The optimal discount rate for a government project is the comparable market rate adjusted for the difference in diversification ability between the government and the private sector if (C31) the government project faces the same non-diversifiable risks as private projects, (C32) the private market fails to eliminate diversifiable risks completely due to some market frictions, and (C33) the government diversifies risks to a larger or smaller extent.

The market interest rate increases with the portion of diversifiable risks that are too costly to diversify. Thus, if the government can diversify risks to a larger extent, the optimal discount rate for a government project is lower than the comparable market rate. Even if the government completely eliminates diversifiable risks, however, the optimal discount rate generally differs from the risk-free rate because nondiversifiable risks remain.

The set of conditions that are satisfied may differ across projects. (C11) can be true for some government projects. The return on a space project, for example, may largely depend on the technological outcome that has little to do with private states. Projects pursuing social outcomes, such as promoting equity, may also produce outcomes unrelated to private states. (C12) may hold to a large extent. With its taxing power, the government can easily distribute the risk among a large number of individuals. (C13) may be generally true, but there may be some exceptions. While most projects are quite small relative to the size of the economy, some programs (e.g., social security and Medicare) may be of considerable size even on the per-capita basis. (C14) is a generally accepted assumption in economics.

(C21) and (C22) should hold for the government projects that can be replicated by private activities in well-functioning markets. Theoretically, the proportion of those projects should not be large because the government is not supposed to intervene in efficient markets. Many government programs, such as those helping students and small businesses, aim to address market failures. In practice, however, the government actively intervenes in well-functioning markets, such as the mortgage market.

(C31) should hold for some government projects, as discussed above. Individuals' abilities to diversify risks have improved substantially. Nevertheless, (C32) may remain true to a certain extent. Many risks are insurable, and mutual funds enable individuals to diversify many financial risks cheaply. Insurance, however, involves sizable administrative costs and profit margins. Furthermore, not all risks are insurable or tradable at a reasonable cost. As a result, many individuals retain some independent risks that are diversifiable in theory. Most individuals heavily depend on the return on human capital. Although the return on individualspecific human capital is largely independent, the risk is hardly pooled. Many individuals are heavily exposed to the housing market risk. Information problems prevent small entrepreneurs from accessing the stock market. The failure to diversify some diversifiable risks may raise the discount 
rates for some private projects. Since the government faces different constraints, (C33) may hold for some projects.

\section{Comparable Market Rates}

As discussed above, it is difficult to determine at the theoretical level whether the optimal discount rate for a government project is a risk-free rate, a market rate, or an adjusted market rate. This section tackles a more manageable problem. If the optimal discount rate for a government project is a market rate, what is the comparable market rate for the project? To achieve social objectives, the government employs various types of intervention and subsidizes some projects whose private (or direct) returns are inferior to market returns. It needs to be clarified what the comparable market rate is for each program.

This section derives optimal discount rates for grants, direct undertaking, direct loans, and loan guarantees under the following assumptions. All projects eligible for a subsidy require an investment of $A$. They are of differing quality. Project $i$ yields $X_{G i} A$ in the good state and $X_{B i} A$ in the bad state. For simplicity, $X_{B}$ is the same for all projects $\left(X_{B i}=\right.$ $X_{B}$ for all $i$ ), so that project quality is represented solely by $X_{G i}$. Each potential beneficiary of the government subsidy has capital $K(K<A)$ and access to a qualifying project. Beneficiaries must borrow $L(A-K)$ to undertake the project. Default occurs in the bad state $\left(X_{B} A<L\right)$. Individuals can diversify in the market, so they are concerned only about the market value of cash flows.

In each case, the government budgets a subsidy $S$. The budget cost is the net present value of the expected cash flows to the government. The optimal discount rate is the one that makes the budget cost equal to the economic cost to taxpayers, which is the market value of the subsidy. The optimal discount rate varies across intervention methods. When the government uses the optimal discount rate for each intervention method, the effect of a given subsidy on investment decisions is the same for all intervention methods.

4.1. Grants. This is the most straightforward case that can serve as a benchmark. The expected cash flows to the government are shown in Table 1 where $S$ is the amount of subsidy, which is equal to the amount of grant.

Since a grant is a simple cash payment in period 0 , both the budget cost $\left(\mathrm{BC}_{1}\right)$ and the economic cost to taxpayers $\left(\mathrm{EC}_{1}\right)$ are $S$, where subscript 1 stands for the case of grants. The discount rate is not applicable for grant programs $\left(R_{D 1}=N A\right)$, where $R_{D}$ is the government discount rate.

The investment decision of beneficiary $i$ (owner of project $i$ ) is to undertake her investment if the sum of the market value of the project cash flows belonging to her and the government subsidy is greater than the market value of her capital. That is,

$$
\frac{1}{\alpha}\left(X_{G i} A-R_{N 1} L\right)+S>K,
$$

where $R_{N}$ is the gross rate on the loan obtained by the project owner. The project owner keeps the project return
TABLE 1

\begin{tabular}{lcc}
\hline & Inflow & Outflow \\
\hline Period 0 & 0 & $S$ \\
Period 1 & 0 & 0 \\
\hline
\end{tabular}

net of loan payment $\left(X_{G i} A-R_{N 1} L\right)$ in the good state and nothing in the bad state. From (3), the prices of the goodstate and the bad-state commodity respectively are $1 / \alpha$ and $1 / \beta$. Thus, the market value of the net project return is $1 / \alpha$ times $\left(X_{G i} A-R_{N 1} L\right)$.

In a competitive credit market, lenders set $R_{N 1}$ such that the market value of the cash flows from the loan equals the amount of loan:

$$
\frac{1}{\alpha} R_{N 1} L+\frac{1}{\beta} X_{B} A=L .
$$

Lenders receive the principal and interest $\left(R_{N 1} L\right)$ in the good state and the project return $\left(X_{B} A\right)$ in the bad state.

Solving (5) for $R_{N 1}$, substituting the solution into (4), and solving (4) for $X_{G i}$,

$$
\begin{aligned}
X_{G i} & >\frac{\left[K-S+\left(L-(1 / \beta) X_{B} A\right)\right] \alpha}{A} \\
& =\frac{\alpha \beta(A-S)-\alpha X_{B} A}{\beta A} \equiv X_{G 1}^{*} .
\end{aligned}
$$

Grants induce only those project owners whose $X_{G i}$ is greater than $X_{G 1}^{*}$.

4.2. Direct Undertaking. When the government undertakes project $i$, the expected cash flows are shown in Table 2.

The budget cost to the government is the amount of investment minus the present value of project cash flows:

$$
\mathrm{BC}_{2}=A-\frac{\pi_{G} X_{G i} A+\pi_{B} X_{B} A}{R_{D 2}},
$$

where subscript 2 stands for the case of direct undertaking.

The economic cost to taxpayers is the amount of investment minus the market value of project cash flows:

$$
\mathrm{EC}_{2}=A-\left(\frac{1}{\alpha} X_{G i} A+\frac{1}{\beta} X_{B} A\right)
$$

The discount rate that makes the budget cost equal to the economic cost is

$$
R_{D 2}^{*}=\frac{\pi_{G} X_{G i} A+\pi_{B} X_{B} A}{(1 / \alpha) X_{G i} A+(1 / \beta) X_{B} A} .
$$

Provided that the intended subsidy for this program is $S$, the government investment decision at this discount rate is to undertake the project if

$$
A-\left(\frac{1}{\alpha} X_{G i} A+\frac{1}{\beta} X_{B} A\right)<S .
$$

The project is worthwhile to undertake if the economic cost to taxpayers is less than the intended subsidy. 
TABLE 2

\begin{tabular}{lcc}
\hline & Inflow & Outflow \\
\hline Period 0 & 0 & $A$ \\
Period 1 & $\pi_{G} X_{G i} A+\pi_{B} X_{B} A$ & 0 \\
\hline
\end{tabular}

Solving for $X_{G i}$,

$X_{G i}>\alpha\left(1-\frac{1}{\beta} X_{B}-\frac{S}{A}\right)=\frac{\alpha \beta(A-S)-\alpha X_{B} A}{\beta A} \equiv X_{G 2}^{*}$.

$R_{D 2}^{*}$ changes with $S$ :

$$
\frac{\partial R_{D 2}^{*}}{\partial S}=\frac{\partial R_{D 2}^{*}}{\partial X_{G}} \frac{\partial X_{G}}{\partial S}=-\frac{\alpha\left(\pi_{G}(1 / \beta)-\pi_{B}(1 / \alpha)\right) X_{B}}{\left((1 / \alpha) X_{G}+(1 / \beta) X_{B}\right)^{2} A} .
$$

4.3. Direct Loans. With direct loans, the expected cash flows to the government are shown in Table 3 where subscript 3 stands for the case of direct loans. The government lends $L$ in period 0 and receives the principal and interest if period 1 turns out to be good and the project return if period 1 turns out to be bad.

The budget cost to the government is

$$
\mathrm{BC}_{3}=L-\frac{\pi_{G} R_{N 3} L+\pi_{B} X_{B} A}{R_{D 3}} .
$$

The economic cost to taxpayers is

$$
\mathrm{EC}_{3}=L-\left(\frac{1}{\alpha} R_{N 3} L+\frac{1}{\beta} X_{B} A\right) .
$$

The discount rate that makes the budget cost equal to the economic cost is

$$
R_{D 3}^{*}=\frac{\pi_{G} R_{N 3} L+\pi_{B} X_{B} A}{(1 / \alpha) R_{N 3} L+(1 / \beta) X_{B} A} .
$$

The investment decision of beneficiary $i$ is to undertake her investment if the market value of the cash flow from the investment is greater than the market value of her capital. The subsidy is implicit in $R_{N 3}$. Algebraically,

$$
\frac{1}{\alpha}\left(X_{G i} A-R_{N 3} L\right)>K .
$$

Provided that the discount rate is $R_{D 3}^{*}$ and the budget for this program is $S$, the government sets $R_{N 3}$, such that the economic cost to taxpayers equals the subsidy:

$$
L-\left(\frac{1}{\alpha} R_{N 3} L+\frac{1}{\beta} X_{B} A\right)=S .
$$

Solving (17) for $R_{N 3}$, substituting the solution to (16), and solving (16) for $X_{G i}$,

$$
\begin{aligned}
X_{G i} & >\frac{\left[K+\left(L-S-(1 / \beta) X_{B} A\right)\right] \alpha}{A} \\
& =\frac{\alpha \beta(A-S)-\alpha X_{B} A}{\beta A} \equiv X_{G 3}^{*} .
\end{aligned}
$$

TABLE 3

\begin{tabular}{lcc}
\hline & Inflow & Outflow \\
\hline Period 0 & 0 & $L$ \\
Period 1 & $\pi_{G} R_{N 3} L+\pi_{B} X_{B} A$ & 0 \\
\hline
\end{tabular}

TABLE 4

\begin{tabular}{lcc}
\hline & Inflow & Outflow \\
\hline Period 0 & $Y$ & 0 \\
Period 1 & 0 & $\pi_{B}\left[R_{N 4}(L+Y)-X_{B} A\right]$ \\
\hline
\end{tabular}

Also in this case, $R_{D 3}^{*}$ changes with $S$ :

$$
\frac{\partial R_{D 3}^{*}}{\partial S}=\frac{\partial R_{D 3}^{*}}{\partial R_{N 3}} \frac{\partial R_{N 3}}{\partial S}=-\frac{\alpha\left(\pi_{G}(1 / \beta)-\pi_{B}(1 / \alpha)\right) X_{B} A}{\left((1 / \alpha) R_{N 3} L+(1 / \beta) X_{B} A\right)^{2}} .
$$

4.4. Loan Guarantees. Assuming that the guarantee fee is financed, the expected cash flows to the government are shown in Table 4 where $Y$ is the upfront guarantee fee and subscript 4 stands for the case of loan guarantees. The guarantee fee must be financed when the project size and the amount of capital are fixed. In the bad state, the government pays out the difference between the loan balance $\left(R_{N 4}(L+Y)\right)$ and the project return $\left(X_{B} A\right)$.

The budget cost to the government is

$$
\mathrm{BC}_{4}=\frac{\pi_{B}\left[R_{N 4}(L+Y)-X_{B} A\right]}{R_{D 4}}-Y .
$$

Economic cost to taxpayers is

$$
\mathrm{EC}_{4}=\frac{1}{\beta}\left[R_{N 4}(L+Y)-X_{B} A\right]-Y .
$$

The discount rate that makes the budget cost equal to the economic cost is

$$
R_{D 4}^{*}=\pi_{B} \beta .
$$

In this case, $R_{D 4}^{*}$ does not vary with $Y$, which is a function of $S$. This is a special case resulting from the assumption of only two states of the world. With a loan guarantee, cash flows occur only in bad states. Thus, when there is only one bad state, cash flows involving $Y$ in the numerator and the denominator cancel out. When there are more than one bad state, however, $R_{D 4}^{*}$ generally varies with $Y$ (see Appendix F).

The investment decision of beneficiary $i$ is to undertake her investment if the market value of the cash flows from the investment is greater than the market value of her capital. The subsidy is implicit in $Y$. Algebraically,

$$
\frac{1}{\alpha}\left[X_{G i} A-R_{N 4}(L+Y)\right]>K .
$$

Provided that the discount rate is $R_{D 4}^{*}$ and the budget for this program is $S$, the government sets $Y$, such that the subsidy equals the market value of the net cash outflow:

$$
S=\frac{1}{\beta}\left[R_{N 4}(L+Y)-X_{B} A\right]-Y .
$$


TABLE 5: Discount rates at which the budget cost equals the economic cost.

\begin{tabular}{rlcccc}
\hline$S$ & $R_{D 1}^{*}$ & $R_{D 2}^{*}$ & $R_{D 3}^{*}$ & $R_{D 4}^{*}$ & 0.75 \\
\hline-1.00 & NA & 1.2273 & 1.2000 & 0.75 & 2.10 \\
-0.50 & NA & 1.2143 & 1.1842 & 0.75 & 1.95 \\
0.00 & NA & 1.2000 & 1.1667 & 0.75 & 1.80 \\
0.50 & NA & 1.1842 & 1.1471 & 0.75 & 0.75 \\
1.00 & NA & 1.1667 & 1.1250 & 0.75 \\
1.50 & NA & 1.1471 & 1.1000 & 1.50 \\
2.00 & NA & 1.1250 & 1.0714 & 1.35 \\
2.50 & NA & 1.1000 & 1.0385 & 0.75 \\
3.00 & NA & 1.0714 & 1.0000 & 0.75 \\
\hline
\end{tabular}

Solving (24) for $Y$, substituting the solution into (23), and solving (23) for $X_{G i}$,

$$
X_{G i}>\frac{\alpha K+R_{N 4}\left(\left(\beta L-X_{B} A-\beta S\right) /\left(\beta-R_{N 4}\right)\right)}{A} \equiv X_{G 4}^{*} .
$$

When the loan is guaranteed by the government, lenders should charge the risk-free rate. It can be shown that when $R_{N 4}=R_{f}$,

$$
X_{G 4}^{*}=\frac{\alpha \beta(A-S)-\alpha X_{B} A}{\beta A} .
$$

4.5. Optimal Discount Rates, Intervention Methods, and Subsidy Rates. The results above can be organized into the following propositions.

Proposition 4. Provided that all agents price risk competitively, the optimal discount rate for a government project is the one at which the budget cost to the government equals the economic cost to taxpayers.

It is optimal for the government to use the discount rate that makes the budget cost equal to the economic cost in two respects: the effect of a subsidy on investment decisions is the same for all intervention methods, and private investment decisions are unaffected when the subsidy is zero. From (6), (11), (18), and (26), $X_{G 1}^{*}=X_{G 2}^{*}=X_{G 3}^{*}=X_{G 4}^{*}$. That is, all four subsidy methods produce the same outcome. Defining that $\theta$ is the share of the government investment in the goodstate project, it can also be shown that $X_{G 1}^{*}=X_{G 2}^{*}=X_{G 3}^{*}=$ $X_{G 4}^{*}=\theta \alpha$ when $S=0$ and $X_{B}=(1-\theta) \beta$. That is, the market outcome is realized when $S=0$. Thus, the government achieves the intended outcome when it uses this discount rate. For these results to hold, however, it is necessary that all agents price risk competitively. For example, if private lenders charged a rate higher than the risk-free rate for a loan fully guaranteed by the government due to imperfect competition or regulation, the subsidy would have to be larger for loan guarantees to have the same effect as other intervention methods.

Proposition 5. The optimal discount rate differs across intervention methods and changes with the subsidy rate.
Each intervention method generates unique cash flows to the government that generally differ from the cash flows generated from the underlying project, and the optimal discount rate is the one reflecting the risk profiles of cash flows to the government. From (9), (15), and (22), $R_{D 2}^{*} \neq R_{D 3}^{*} \neq R_{D 4}^{*}$. The project risk is optimally priced when every agent including the government optimally prices the risk of its own cash flows, that is, when all agents use the discount rate reflecting the risk profiles of their own cash flows. The government does not need to consider the ultimate cash flows to taxpayers. The optimal discount rate changes with the subsidy rates because subsidies change the cash flows to the government.

4.6. Simulation. To illustrate the above analyses, I derive numerical results under the following assumptions: $\alpha=3$, $\beta=1.5, \pi_{1 G}=0.5, \pi_{1 B}=0.5, A=10, D=9, K=1$, and $X_{B}=0.6$. Under these assumptions, $p_{1 G}=1 / 3, p_{1 B}=2 / 3$, and $R_{f}=1$. Table 5 shows the discount rate that makes the budget cost to the government equal to the economic cost to taxpayers for each intervention method at different subsidy levels.

At each subsidy level, $X_{G}^{*}$ is the same for all intervention methods, meaning that they equally affect the incentives of beneficiaries. $X_{G}^{*}=1.8$ when the subsidy is zero. Since $X_{B}$ is assumed to be 0.6 , the market value of the project cash flows is the same as the value of investment when $X_{G}^{*}=1.8$. Thus, zero-subsidy intervention does not disturb the market outcome if the discount rate is optimal.

The optimal discount rate is lower for direct loans than for direct undertaking because risk is first absorbed by borrowers. Interestingly, while the optimal discount rate for direct loans is higher than the risk-free rate, it is lower than the risk-free rate for loan guarantees (The result will be reversed if default occurs in the good state. While this may be possible for some government programs, default should occur in the bad state for most credit programs.). The reason is that direct loans generate good-state cash inflows that are less valuable than risk-free cash flows and loan guarantees generate bad-state cash outflows that are more valuable than risk-free cash flows. Thus, discounting both cash flows with the risk-free rate does not necessarily favor direct loans. While the use of the risk-free rate overstates cash inflows (loan repayment) for direct loans, it understates 
cash outflows (guarantee payouts) of loan guarantees. If the optimal discount rate were higher than the risk-free rate for both direct loans and loan guarantees, discounting with the risk-free rate would favor direct loans by overstating cash inflows for direct loans and overstating cash outflows for loan guarantees. This assumption, however, is generally invalid.

Ignoring the cash flow effect of subsidies can lead to serious distortion. In the table, the optimal discount rate for direct loans is 1.1667 when the subsidy is zero and 1.0000 when the subsidy is 3 (30 percent of project size). When the subsidy is large, therefore, using the "optimal" discount rate derived under the assumption of no subsidy (1.1667) can be even worse than discounting with the riskfree rate (1.0000). As discussed above, the constant discount rate for loan guarantees is a special case resulting from the assumption of only one bad state.

\section{Conclusion}

The optimal discount rate for a government project is project specific. It can be a risk-free rate, a market rate, or an adjusted market rate, depending on circumstances. Even when a market rate is optimal, the comparable market rate varies across intervention methods and changes with the subsidy rate.

Ideally, the government should estimate social costs and benefits in all possible states and price state-contingent returns using market information. This task would be practically impossible. A practical alternative is to apply market rates to those government projects that have return profiles similar to those of private projects, while using a risk-free rate for those projects without private counterparts. This approach has several limitations, however. The lack of private counterparts does not necessarily mean that project returns are independent of private states. In the sectors where market failures exist, market prices do not exist or are misleading. Government intervention itself can distort market prices even in well-functioning markets, such as the mortgage market.

In sectors where the government diversifies better, there can be substantial gaps between market rates and optimal rates. Many government projects pursuing social objectives may involve externalities. When social returns differ from private returns, market rates reflecting only private returns are inappropriate for government projects.

Obviously, applying a uniform discount rate to all government projects is problematic. A uniform discount rate distorts investment decisions by favoring some projects over others. Without knowing the risk composition of government projects, it would be also difficult to select the best uniform discount rate (e.g., a risk-free rate or the average market rate). Nevertheless, a uniform discount rate can still be the second best if obtaining project-specific discount rates is extremely difficult.

Considering all the complexities discussed in this paper, obtaining the optimal discount rate may be difficult for many projects. However, there are some straightforward cases. If a public pension fund invests in stocks, for example, it should discount stock returns with the market rate and value its investment at the market price; the government and private investors face the same risk, and diversification is easy both for the government and private entities. Therefore, although a sweeping reform may require empirical studies thoroughly looking at the nature and composition of government projects, a relatively safe step may be to proceed cautiously and gradually toward project-specific optimal discount rates, starting from the most obvious cases.

\section{Appendices}

\section{A. Discount Rates and State-Dependent Cash Flows}

Since $E\left(q_{1 G}\right)=1$ when $q_{1 G}=1 / \pi_{G}$ and $E\left(q_{1 B}\right)=1$ when $q_{1 B}=1 / \pi_{B}$, the price per expected unit is $p_{1 G} / \pi_{G}$ for the good-state commodity and $p_{1 B} / \pi_{B}$ for the bad-state commodity. Thus, the discount factors for the good-state and the bad-state commodity are

$$
\begin{aligned}
& R_{G}=\left(1+r_{G}\right)=\frac{\pi_{G}}{p_{1 G}}=\pi_{G} \alpha, \\
& R_{B}=\left(1+r_{B}\right)=\frac{\pi_{B}}{p_{1 B}}=\pi_{B} \beta .
\end{aligned}
$$

At the discount rates of $r_{G}$ and $r_{B}$, the present values of the expected cash flows equal the prices. Since $\pi_{G} \alpha>\pi_{B} \beta, R_{G}>$ $R_{B}$.

The price of a certain unit of the period-1 commodity is

$$
p_{1}=p_{1 G}+p_{1 B}=\frac{1}{\alpha}+\frac{1}{\beta}=\frac{\alpha+\beta}{\alpha \beta} .
$$

The risk-free discount factor is

$$
R_{f}=\left(1+r_{f}\right)=\frac{\pi_{G}+\pi_{B}}{p_{1}}=\frac{\alpha \beta}{\alpha+\beta} .
$$

The price of a combination of period-1 commodities $\left(q_{1 G}, q_{1 B}\right)$ is

$$
p_{1 G B}=p_{1 G} q_{1 G}+p_{1 B} q_{1 B}=\frac{1}{\alpha} q_{1 G}+\frac{1}{\beta} q_{1 B}=\frac{\beta q_{1 G}+\alpha q_{1 B}}{\alpha \beta} .
$$

The discount factor for this package of future commodities is

$$
R_{G B}=\left(1+r_{G B}\right)=\frac{\pi_{G} q_{1 G}+\pi_{B} q_{1 B}}{p_{1 G B}}=\frac{\alpha \beta\left(\pi_{G} q_{1 G}+\pi_{B} q_{1 B}\right)}{\beta q_{1 G}+\alpha q_{1 B}} .
$$

Holding $q_{1 B}$ constant, $R_{1 G B}$ increases with $q_{1 G}$ :

$\frac{\partial R_{G B}}{\partial q_{1 G}}=\alpha \beta q_{1 B}\left(\pi_{G} \alpha-\pi_{B} \beta\right)>0 \quad$ since $\pi_{G} \alpha>\pi_{B} \beta$. 


\section{B. Government Projects with State-Dependent Returns}

Suppose that the government finances a project with bond issuance. In period 0 , the government borrows $B$ from the public at the interest rate of $r_{f}$ and invests the proceeds in projects yielding state-dependent returns. In period 1 , the government repays $R_{f}$ to the lenders and distributes the net return on the investment to the public through taxation (rebate if the net return is positive). Since individuals have the identical preference and endowment, everybody lends the same amount $(b=B / N$, where $N$ is the number of individuals) to the government.

With the government investment, the individual budget constraint becomes

$$
c_{0}^{\prime}+p_{1 G} c_{1 G}^{\prime}+p_{1 B} c_{1 B}^{\prime}+b \leq 1,
$$

where $c^{\prime}$ is the amount of consumption chosen by individuals, excluding payments to and from the government. The final consumption reflecting bond purchase, bond repayment, and taxes is

$$
\begin{gathered}
c_{0}=c_{0}^{\prime}=1-p_{1 G} c_{1 G}^{\prime}-p_{1 B} c_{1 B}^{\prime}-b, \\
c_{1 G}=c_{1 G}^{\prime}+R_{f} b-t_{G}, \\
c_{1 B}=c_{1 B}^{\prime}+R_{f} b-t_{B},
\end{gathered}
$$

where $t_{s}$ is the per-capita tax in state $s$ :

$$
\begin{gathered}
t_{G}=R_{f} b-\theta \alpha_{Z} b, \\
t_{B}=R_{f} b-(1-\theta) \beta_{Z} b,
\end{gathered}
$$

where $\theta$ is the share of the borrowing invested in the good-state project and $\alpha_{Z}$ and $\beta_{Z}$ are $\alpha$ and $\beta$ for the government project. The tax is the difference between the bond repayment and the return on the government project.

By (B.2) and (B.3), (B.1) becomes

$$
c_{0}+p_{1 G} c_{1 G}+p_{1 B} c_{1 B} \leq 1-W,
$$

where $W=\left[1-\theta\left(\alpha_{Z} / \alpha\right)-(1-\theta)\left(\beta_{Z} / \beta\right)\right] b$. Given this, individuals in effect have more resources to spend when $W<0$ and less resources when $W>0$. Clearly, $W=0$ when $\alpha_{Z}=\alpha$ and $\beta_{Z}=\beta$. $W<0$ when $\alpha_{Z}>\alpha$ and $\beta_{Z}=\beta$ or when $\alpha_{Z}=\alpha$ and $\beta_{Z}>\beta$. Solving for $\alpha_{Z}, W<0$ if $\alpha_{Z}>\alpha\left(\beta-(1-\theta) \beta_{Z}\right) / \theta \beta$. W $>$ in the opposite cases.

The same conditions can be derived from the NPV rule. Since $q_{1 G}=\theta \alpha_{Z} b$ and $q_{1 B}=(1-\theta) \beta_{Z} b$, the expected return on the government project is $\pi_{G} \theta \alpha_{Z} b+\pi_{B}(1-\theta) \beta_{Z} b$. Discounting this expected return with $R_{G B}$ in (A.5), NPV is $\left(\left(\beta \theta \alpha_{Z} b+\alpha(1-\theta) \beta_{Z} b\right) / \alpha \beta\right)-b$. When it is solved for $\alpha_{Z}$, the condition that NPV $>0$ is the same as the condition that $W<0$.

Now suppose that the government taxes $t_{0}$ per capita to invest in a project and distributes the return on the project in the second period. Then, the budget constraint becomes

$$
c_{0}^{\prime}+p_{1 G} c_{1 G}^{\prime}+p_{1 B} c_{1 B}^{\prime}+t_{0} \leq 1 .
$$

The final consumption after taxes and distributions is

$$
\begin{gathered}
c_{0}=c_{0}^{\prime}, \\
c_{1 G}=c_{1 G}^{\prime}+\theta \alpha_{Z} t_{0}, \\
c_{1 B}=c_{1 B}^{\prime}+(1-\theta) \beta_{Z} t_{0} .
\end{gathered}
$$

By (B.6), (B.5) becomes

$$
c_{0}+p_{1 G} c_{1 G}+p_{1 B} c_{1 B} \leq 1-\left[1-\theta \frac{\alpha_{Z}}{\alpha}-(1-\theta) \frac{\beta_{Z}}{\beta}\right] t_{0} .
$$

Equation (B.7) is identical to (B.4) when $b=t_{0}$, and hence the welfare-maximizing investment rules are the same for tax financing.

\section{Government Projects with State-Independent Returns}

Suppose that a government project yields either a high or a low return in period 1 , independent of the private state. The probability of the high return is the same in both the good and the bad states. The expected return on this government project is

$$
E\left(R_{Z}\right)=\pi_{H} R_{H}+\pi_{L} R_{L},
$$

where subscripts $H$ and $L$ stand for the high return and the low return.

The period- 1 consumption is

$$
\begin{gathered}
c_{1 G} \begin{cases}c_{1 G H}=c_{1 G}^{\prime}+R_{f} b-t_{H} & \text { with probability } \pi_{H}, \\
c_{1 G L}=c_{1 G}^{\prime}+R_{f} b-t_{L} & \text { with probability } \pi_{L},\end{cases} \\
c_{1 B} \begin{cases}c_{1 B H}=c_{1 B}^{\prime}+R_{f} b-t_{H} & \text { with probability } \pi_{H}, \\
c_{1 B L}=c_{1 B}^{\prime}+R_{f} b-t_{L} & \text { with probability } \pi_{L} .\end{cases}
\end{gathered}
$$

Taxes are

$$
\begin{gathered}
t_{H}=R_{f} b-R_{H} b=\left(R_{f}-R_{H}\right) b=\left(R_{f}-R_{H}\right) \frac{B}{N}, \\
t_{L}=R_{f} b-R_{L} b=\left(R_{f}-R_{L}\right) b=\left(R_{f}-R_{L}\right) \frac{B}{N} .
\end{gathered}
$$

The gap between $t_{H}$ and $t_{L}$ increases with $B$ and decreases with $N$.

The expected utility is

$$
\begin{gathered}
E(U)=v\left(c_{0}\right)+\frac{\pi_{G}\left[\pi_{H} v\left(c_{1 G H}\right)+\pi_{L} v\left(c_{1 G L}\right)\right]}{1+\rho} \\
+\frac{\pi_{B}\left[\pi_{H} v\left(c_{1 B H}\right)+\pi_{L} v\left(c_{1 B L}\right)\right]}{1+\rho} .
\end{gathered}
$$

When the government project is small relative to the size of the economy (small $B$ and large $N$ ), the gap between $c_{1 G H}$ and $c_{1 G L}$ and the gap between $c_{1 B H}$ and $c_{1 B L}$ are small. Thus,

$$
E(U) \approx v\left(c_{0}\right)+\frac{\pi_{G} v\left(E\left(c_{1 G}\right)\right)}{1+\rho}+\frac{\pi_{B} v\left(E\left(c_{1 B}\right)\right)}{1+\rho} .
$$

Since $v$ exhibits constant relative risk aversion, both the percapita and the aggregate cost of risk bearing decrease with $N$ and increase with $B$. 


\section{Lower Diversification Costs for the Government}

For simplicity, let us assume that the effective price for individuals is higher only for the bad-state commodity and that $\alpha$ and $\beta$ are effective returns net of the transactions cost. Government projects yield the same return, but the effective return is higher in the bad state thanks to a lower transactions cost $\left(\beta_{Z}>\beta\right)$. If the government can deliver $\left\{\alpha \theta B, \beta_{Z}(1-\right.$ $\theta) B\}$, instead of $\{\alpha \theta B, \beta(1-\theta) B\}$, to individuals, it is rather obvious that this project makes individuals better off.

The market prices of commodities are determined by the returns that investors receive. When the private sector undertakes this project, the market value of the investor return is

$$
\mathrm{MV}=\frac{1}{\alpha} \alpha \theta B+\frac{1}{\beta} \beta(1-\theta) B=B
$$

When the government undertakes this project, the market value of the project return to individuals is

$$
\begin{aligned}
\mathrm{MV}_{Z} & =\frac{1}{\alpha} \alpha \theta B+\frac{1}{\beta} \beta_{Z}(1-\theta) B \\
& =B+\left(\beta_{Z}-\beta\right)\left\{\frac{1}{\beta}(1-\theta) B\right\}>B .
\end{aligned}
$$

Given that $\mathrm{MV}_{Z}>\mathrm{MV}, R_{G B Z}<R_{G B}$ because the market discount factor is the inverse of the market price per expected unit (Another way to represent a superior diversification ability of the government is to assume a higher relative return in the bad state, holding the expected return constant. Since the bad-state commodity is more valuable, the qualitative result will remain the same in this case; the market value of the government project is higher than $B$, and individuals are better off with the government project.). Thus, when the government has a superior ability to diversify, the optimal discount rate for the government is lower than the market discount rate for a similar project.

\section{E. Simulation Results for Different Return Distributions}

This simulation shows how the return distribution affects individuals' utility when the government undertakes a project yielding the risk-free rate of return. Three return distributions are considered: the project is subject to the same uncertainty faced by the private sector and yields a higher return in the good state (unfavorable risk profile); it is subject to the same uncertainty but yields a higher return in the bad state (favorable risk profile); its return is independent of the state of the private sector (independent risk profile).

For this simulation, the maximization problem needs to be solved first. From (1) and (2), the maximization problem is

$$
\begin{aligned}
L\left(c_{0}, c_{1 G}, c_{1 B}, \lambda\right)= & v\left(c_{0}\right)+\frac{\pi_{G} v\left(c_{1 G}\right)}{1+\rho}+\frac{\pi_{B} v\left(c_{1 B}\right)}{1+\rho} \\
& -\lambda\left(c_{0}+p_{1 G} c_{1 G}+p_{1 B} c_{1 B}-1\right) .
\end{aligned}
$$

The optimality conditions are

$$
\begin{gathered}
\frac{\partial L}{\partial c_{0}}=\frac{\partial v}{\partial c_{0}}-\lambda=0, \\
\frac{\partial L}{\partial c_{1 G}}=\frac{\partial v}{\partial c_{1 G}} \frac{\pi_{G}}{1+\rho}-\lambda p_{1 G}=0, \\
\frac{\partial L}{\partial c_{1 B}}=\frac{\partial v}{\partial c_{1 B}} \frac{\pi_{B}}{1+\rho}-\lambda p_{1 B}=0, \\
\frac{\partial L}{\partial \lambda}=c_{0}+p_{1 G} c_{1 G}+p_{1 B} c_{1 B}-1=0 .
\end{gathered}
$$

I assume a widely used utility function exhibiting constant relative risk aversion:

$$
v=\frac{1}{1-\gamma} c^{1-\gamma},
$$

where $\gamma$ is a positive constant other than 1. Risk aversion (the curvature of $v$ with respect $c$ ) increases with $\gamma$.

With this utility function, the optimality conditions are

$$
\begin{gathered}
\frac{c_{0}^{-\gamma}}{c_{1 G}^{-\gamma}}=\frac{\pi_{G}}{p_{1 G}(1+\rho)}, \\
\frac{c_{0}^{-\gamma}}{c_{1 B}^{-\gamma}}=\frac{\pi_{B}}{p_{1 B}(1+\rho)}, \\
c_{0}+p_{1 G} c_{1 G}+p_{1 B} c_{1 B}=1 .
\end{gathered}
$$

Solving these three equations for $c_{0}, c_{1 G}$, and $c_{1 B}$, the optimal levels of consumption are

$$
\begin{gathered}
c_{0}^{*}=\frac{(1+\rho)^{1 / \gamma}}{(1+\rho)^{1 / \gamma}+p_{1 G}^{1-1 / \gamma} \pi_{G}^{1 / \gamma}+p_{1 B}^{1-1 / \gamma} \pi_{B}^{1 / \gamma}}, \\
c_{1 G}^{*}=\frac{\pi_{G}^{1 / \gamma}}{p_{1 G}^{1 / \gamma}(1+\rho)^{1 / \gamma}+p_{1 G} \pi_{G}^{1 / \gamma}+p_{1 G}^{1 / \gamma} p_{1 B}^{1-1 / \gamma} \pi_{B}^{1 / \gamma}}, \\
c_{1 B}^{*}=\frac{\pi_{B}^{1 / \gamma}}{p_{1 B}^{1 / \gamma}(1+\rho)^{1 / \gamma}+p_{1 B} \pi_{B}^{1 / \gamma}+p_{1 B}^{1 / \gamma} p_{1 G}^{1-1 / \gamma} \pi_{G}^{1 / \gamma}} .
\end{gathered}
$$

The following parameter values are assumed for simulation: $\gamma=3, \rho=0, \alpha=3, \beta=1.5, \pi_{1 G}=0.5$, and $\pi_{1 B}=0.5$. Under these assumptions, $p_{1 G}=1 / 3, p_{1 B}=2 / 3, R_{f}=1, c_{0}^{*}=$ $0.5032, c_{1 G}^{*}=0.5760, c_{1 B}^{*}=0.4572$, and $E(v)=-3.9242$.

Suppose that the government invests 1 unit in a project with an unfavorable risk profile, yielding 1.5 units in the good state and 0.5 unit in the bad state. The NPV would be 0 if the project were discounted by the risk-free rate. However, the market value of the cash flows from this project is 0.8333 . Table 6 shows that sharing this loss does not really reduce the total loss (The total loss modestly decreases with $N$ because more inframarginal units are lost when $N$ is smaller. Because of diminishing marginal utility, the utility from an inframarginal unit is larger than that from a very marginal unit. This effect, however, is likely to be very small.). For this project, the optimal discount rate is higher than the risk-free rate. 
TABLE 6: Utility loss from a government project with an unfavorable risk profile.

\begin{tabular}{lllcccc}
\hline$N$ & $B$ & $b$ & $E(v)_{Z}$ & $E(v)$ & Per-capita utility loss & Total utility loss \\
\hline 10 & 1 & 0.1 & -4.058304 & -3.924154 & 0.134149 & 1.341495 \\
100 & 1 & 0.01 & -3.937268 & -3.924154 & 0.013113 & 1.311329 \\
1000 & 1 & 0.001 & -3.925463 & -3.924154 & 0.001308 & 1.308378 \\
10000 & 1 & 0.0001 & -3.924285 & -3.924154 & 0.000131 & 1.308084 \\
100000 & 1 & 0.00001 & -3.924167 & -3.924154 & $1.3081 E-05$ & 1.308055 \\
1000000 & 1 & 0.000001 & -3.924156 & -3.924154 & $1.3081 E-06$ & 1.308052 \\
10000000 & 1 & 0.0000001 & -3.924154 & -3.924154 & $1.3081 E-07$ & 1.308051 \\
100000000 & 1 & 0.00000001 & -3.924154 & -3.924154 & $1.3081 E-08$ & 1.308051 \\
1000000000 & 1 & $1 E-09$ & -3.924154 & -3.924154 & $1.3081 E-09$ & \\
\hline
\end{tabular}

TABLE 7: Utility loss from a government project with a favorable risk profile.

\begin{tabular}{lllcccc}
\hline$N$ & $B$ & $b$ & $E(v)_{Z}$ & $E(v)$ & Per-capita utility loss & Total utility loss \\
\hline 10 & 1 & 0.1 & -3.796548 & -3.924154 & -0.127606 & -1.276062 \\
100 & 1 & 0.01 & -3.911106 & -3.924154 & -0.013048 & -1.304789 \\
1000 & 1 & 0.001 & -3.922846 & -3.924154 & -0.001308 & -1.307724 \\
10000 & 1 & 0.0001 & -3.924023 & -3.924154 & -0.000131 & -1.308019 \\
100000 & 1 & 0.00001 & -3.924141 & -3.924154 & $-1.3081 E-05$ & -1.308051 \\
1000000 & 1 & 0.000001 & -3.924153 & -3.924154 & $-1.3081 E-06$ & -1.308051 \\
10000000 & 1 & 0.0000001 & -3.924154 & -3.924154 & $-1.3081 E-07$ & -1.308051 \\
100000000 & 1 & 0.00000001 & -3.924154 & -3.924154 & $-1.3081 E-08$ & -1.308051 \\
1000000000 & 1 & $1 E-09$ & -3.924154 & -3.924154 & $-1.3081 E-09$ & \\
\hline
\end{tabular}

Now consider a project with a favorable risk profile, yielding 0.5 unit in the good state and 1.5 units in the bad state per unit invested. Since the bad-state cash flow is more valuable, the market value of the cash flows is 1.1667 . Table 7 shows that individuals gain from this project (negative loss). For this project, the optimal discount rate is lower than the risk-free rate.

The next case is a government project with an independent risk profile: investment $=1, R_{H}=1.5, R_{L}=0.5$, $\pi_{H}=0.5$, and $\pi_{L}=0.5$. Table 8 shows that the utility loss at the aggregated level, as well as that at the individual level, converges to zero as the number of individuals sharing the risk increases. Thus, the optimal discount rate for this project is close to the risk-free rate when the project size is small and the number of individuals is large.

\section{F. Optimal Discount Rates for Loan Guarantees with Two Bad States}

With two bad states, the budget cost to the government is

$$
\begin{aligned}
\mathrm{BC}_{4}= & \frac{\pi_{B \mathrm{I}}\left[R_{N 4}(L+Y)-X_{B \mathrm{I}} A\right]}{R_{D 4}} \\
& +\frac{\pi_{B \mathrm{II}}\left[R_{N 4}(L+Y)-X_{B \mathrm{II}} A\right]}{R_{D 4}}-Y,
\end{aligned}
$$

where subscripts I and II stand for bad state I and bad state II.
The economic cost to taxpayers is

$$
\begin{aligned}
\mathrm{EC}_{4}= & \frac{1}{\beta_{\mathrm{I}}}\left[R_{N 4}(L+Y)-X_{B \mathrm{I}} A\right] \\
& +\frac{1}{\beta_{\mathrm{II}}}\left[R_{N 4}(L+Y)-X_{B \mathrm{II}} A\right]-Y .
\end{aligned}
$$

The discount rate that makes the accounting cost equal to the economic cost is

$$
\begin{aligned}
& R_{D 4}^{*} \\
= & \frac{\pi_{B \mathrm{I}}\left[R_{N 4}(L+Y)-X_{B \mathrm{I}} A\right]+\pi_{B \mathrm{II}}\left[R_{N 4}(L+Y)-X_{B \mathrm{II}} A\right]}{\left(1 / \beta_{\mathrm{I}}\right)\left[R_{N 4}(L+Y)-X_{B \mathrm{I}} A\right]+\left(1 / \beta_{\mathrm{II}}\right)\left[R_{N 4}(L+Y)-X_{B \mathrm{II}} A\right]}, \\
\frac{\partial R_{D 4}^{*}}{\partial Y} & \frac{\left(\pi_{B \mathrm{I}}\left(1 / \beta_{\mathrm{II}}\right)-\pi_{B \mathrm{II}}\left(1 / \beta_{\mathrm{I}}\right)\right)}{\left\{\left(1 / \beta_{\mathrm{I}}\right)\left[R_{N 4}(L+Y)-X_{B \mathrm{I}} A\right]+\left(1 / \beta_{\mathrm{II}}\right)\left[R_{N 4}(L+Y)-X_{B \mathrm{II}} A\right]\right\}^{2}} \\
& \times R_{N 4}\left\{\left[R_{N 4}(L+Y)-X_{B \mathrm{II}} A\right]-\left[R_{N 4}(L+Y)-X_{B \mathrm{II}} A\right]\right\} \\
= & \frac{\left(\pi_{B \mathrm{I}}\left(1 / \beta_{\mathrm{II}}\right)-\pi_{B \mathrm{II}}\left(1 / \beta_{\mathrm{I}}\right)\right) R_{N 4} A\left(X_{B \mathrm{I}}-X_{B \mathrm{II}}\right)}{\left\{\left(1 / \beta_{\mathrm{I}}\right)\left[R_{N 4}(L+Y)-X_{B \mathrm{I}} A\right]+\left(1 / \beta_{\mathrm{II}}\right)\left[R_{N 4}(L+Y)-X_{B \mathrm{II}} A\right]\right\}^{2}}, \\
& \frac{\partial R_{D 4}^{*}}{\partial Y}=0 \quad \text { only if } \frac{\pi_{B \mathrm{I}}}{\beta_{\mathrm{II}}}=\frac{\pi_{B \mathrm{II}}}{\beta_{\mathrm{I}}} .
\end{aligned}
$$

Since $\partial R_{D 4}^{*} / \partial Y$ is generally not zero, $R_{D 4}^{*}$ generally changes with $Y$ and $S$. 
TABLE 8: Utility loss from a government project with an independent risk profile.

\begin{tabular}{lllcccc}
\hline$N$ & $B$ & $b$ & $E(v)_{Z}$ & $E(v)$ & Per-capita utility loss & Total utility loss \\
\hline 10 & 1 & 0.1 & -3.985188 & -3.924154 & 0.06103367 & 0.61033670 \\
100 & 1 & 0.01 & -3.924754 & -3.924154 & 0.00059958 & 0.05995816 \\
1000 & 1 & 0.001 & -3.924160 & -3.924154 & $5.9948 E-06$ & 0.00599476 \\
10000 & 1 & 0.0001 & -3.924154 & -3.924154 & $5.9947 E-08$ & 0.00059947 \\
100000 & 1 & 0.00001 & -3.924154 & -3.924154 & $5.9948 E-10$ & $5.9948 E-05$ \\
1000000 & 1 & 0.000001 & -3.924154 & -3.924154 & $5.9948 E-12$ & $5.9948 E-06$ \\
10000000 & 1 & 0.0000001 & -3.924154 & -3.924154 & $6.0396 E-14$ & $6.0396 E-07$ \\
100000000 & 1 & 0.00000001 & -3.924154 & -3.924154 & $8.8818 E-16$ & $8.8818 E-08$ \\
1000000000 & 1 & $1 E-09$ & -3.924154 & -3.924154 & 0 & 0 \\
\hline
\end{tabular}

\section{Notations}

A : $\quad$ Required amount of investment in subsidy-eligible projects

B: $\quad$ Amount of government borrowing to finance the project

$b$ : Amount of government borrowing per capita to finance the project

BC: Budget cost to the government

$c_{0}$ : Period-0 consumption

$c_{1 G}$ : Period-1 consumption if the good state is realized

$c_{1 B}$ : Period- 1 consumption if the bad state is realized

$c_{0}^{*}$ : Optimal level of period-0 consumption

$c_{1 G}^{*}$ : Optimal level of period-1 consumption if the good state is realized

$c_{1 B}^{*}$ : Optimal level of period-1 consumption if the bad state is realized

$c_{0}^{\prime}$ : $\quad$ Amount of period-1 consumption chosen by individuals, excluding payments to and from the government

$c_{1 G}^{\prime}$ : Amount of good-state consumption chosen by individuals, excluding payments to and from the government

$c_{1 B}^{\prime}$ : Amount of bad-state consumption chosen by individuals, excluding payments to and from the government

$c_{1 G H}$ : Period-1 consumption if the good state and the high return are realized

$c_{1 G L}$ : Period- 1 consumption if the good state and the low return are realized

$c_{1 B H}$ : Period-1 consumption if the bad state and the high return are realized

$c_{1 B L}$ : Period-1 consumption if the bad state and the low return are realized

EC: Economic cost to taxpayers

$I_{G}$ : Good-state investment

$I_{B}$ : Bad-state investment

$K$ : $\quad$ Amount of equity capital available for a subsidy-eligible project

L: $\quad$ Amount of loan required to undertake a subsidy-eligible project

MV: Market value

$\mathrm{MV}_{Z}$ : Market value of the government project
$N$ : Number of individuals

NPV: Net present value

$\mathrm{NPV}_{Z}$ : Net present value of the government project

$p_{1}$ : $\quad$ Price of a certain unit of the period-1 commodity

$p_{1 G}$ : Per-unit price of commodity to be delivered in period 1 if the good state is realized

$p_{1 B}$ : Per-unit price of commodity to be delivered in period 1 if the bad state is realized

$p_{1 G B}$ : Price of a combination of period-1 commodities

$p_{1 G B}^{*}$ : Price of the optimal consumption bundle

$q_{1 G}: \quad$ Quantity of the good-state commodity

$q_{1 B}: \quad$ Quantity of the bad-state commodity

$R_{D}$ : Government discount factor

$R_{D}^{*}: \quad R_{D}$ at which the accounting cost to the government equals the economic cost to taxpayers

$R_{f}: \quad$ Risk-free discount factor

$R_{G}$ : Time-state discount factor for the good-state commodity

$R_{B}$ : Time-state discount factor for the bad-state commodity

$R_{G B}$ : Discount factor for a combination of period-1 commodities

$R_{G B}^{*}$ : Discount factor for the optimal consumption bundle

$R_{G B Z}: \quad R_{G B}$ for the government

$R_{H}$ : High return on the government project

$R_{L}$ : Low return on the government project

$R_{N}$ : Gross lending rate

$R_{Z}$ : Return on the government project

$r_{f}: \quad$ Risk-free discount rate

$r_{G}$ : Time-state discount rate for the good-state commodity

$r_{B}$ : Time-state discount rate for the bad-state commodity

$r_{G B}$ : Discount rate for a combination of period-1 commodities

$r_{G B}^{*}: \quad$ Discount rate for the optimal consumption bundle

S: $\quad$ Amount of subsidy

$t_{0}$ : Per-capita tax to finance the government project in period 0 
$t_{G}$ : Per-capita tax in the good state

$t_{B}$ : Per-capita tax in the bad state

$t_{H}$ : Per-capita tax when the high return is realized on the government project

$t_{L}$ : Per-capita tax when the low return is realized on the government project

$v$ : Cardinal utility function exhibiting constant relative risk aversion

$X_{G i}$ : Per-unit return on subsidy-eligible project $i$ in the good state

$X_{G i}^{*}$ : Marginal $X_{G i}$ that make project $i$ attractive

$X_{B i}$ : Per-unit return on subsidy-eligible project $i$ in the bad state

$X_{B}$ : Per-unit return on subsidy-eligible projects in the good state

$Y$ : Upfront loan guarantee fee

$\alpha$ : Per-unit return on the good-state investment

$\beta$ : Per-unit return on the bad-state investment

$\alpha_{Z}: \alpha$ for the government project

$\beta_{Z}: \beta$ for the government project

$\theta$ : Share of the government investment in the good-state project

$\pi_{G}$ : Probability that the good state is realized

$\pi_{B}$ : Probability that the bad state is realized

$\pi_{H}$ : Probability that the high return is realized

$\pi_{L}$ : Probability that the low return is realized

$\rho$ : Time discount rate.

\section{Acknowledgments}

The views expressed are the author's own and do not necessarily reflect those of the Office of Management and Budget. The author thanks three editors for helpful comments and suggestions.

\section{References}

[1] C. Gollier, "Discounting an uncertain future," Journal of Public Economics, vol. 85, no. 2, pp. 149-166, 2002.

[2] B. Groom, C. Hepburn, P. Koundouri, and D. Pearce, "Declining discount rates: the long and the short of it," Environmental and Resource Economics, vol. 32, no. 4, pp. 445-493, 2005.

[3] M. A. Moore, A. E. Boardman, A. R. Vining, D. L. Weimer, and D. H. Greenberg, “"Just give me a number!" Practical values for the social discount rate," Journal of Policy Analysis and Management, vol. 23, no. 4, pp. 789-812, 2004.

[4] M. L. Weitzman, "Gamma discounting," American Economic Review, vol. 91, no. 1, pp. 260-271, 2001.

[5] R. J. Zeckhauser and W. K. Viscusi, "Discounting dilemmas: editors' introduction," Journal of Risk and Uncertainty, vol. 37, no. 2-3, pp. 95-106, 2008.

[6] K. J. Arrow and R. C. Lind, "Uncertainty and the evaluation of public investment decisions," American Economic Review, vol. 60, no. 3, pp. 364-378, 1970.

[7] P. A. Samuelson, "Discussion," American Economic Review, vol. 54, no. 3, pp. 93-96, 1964.

[8] W. Vickrey, "Discussion," American Economic Review, vol. 54, no. 3, pp. 88-92, 1964.

[9] J. Hirshleifer, "Investment decision under uncertainty: applications of the state-preference approach," Quarterly Journal of Economics, vol. 80, no. 2, pp. 252-277, 1966.
[10] P. A. Diamond, "The role of a stock market in a general equilibrium model with technological uncertainty," American Economic Review, vol. 57, no. 4, pp. 759-776, 1967.

[11] A. Sandmo, "Discount rates for public investment under uncertainty," International Economic Review, vol. 13, no. 2, pp. 287-302, 1972.

[12] C. Bazelon and K. Smetters, "Discounting inside the Washington D.C. beltway," Journal of Economic Perspectives, vol. 13, no. 4, pp. 213-228, 1999.

[13] D. Lucas and M. Phaup, "The cost of risk to the government and its implications for federal budgeting," in Measuring and Managing Federal Financial Risk, pp. 29-54, University of Chicago Press, Chicago, Ill, USA, 2010.

[14] J. Hirshleifer, Investment, Interest and Capital, Prentice-Hall, Englewood Cliffs, NJ, USA, 1970. 


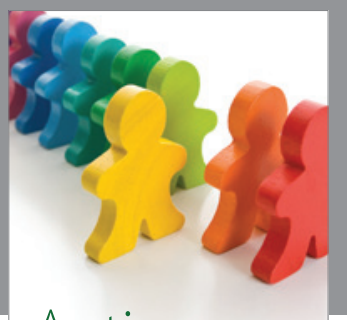

Autism

Research and Treatment
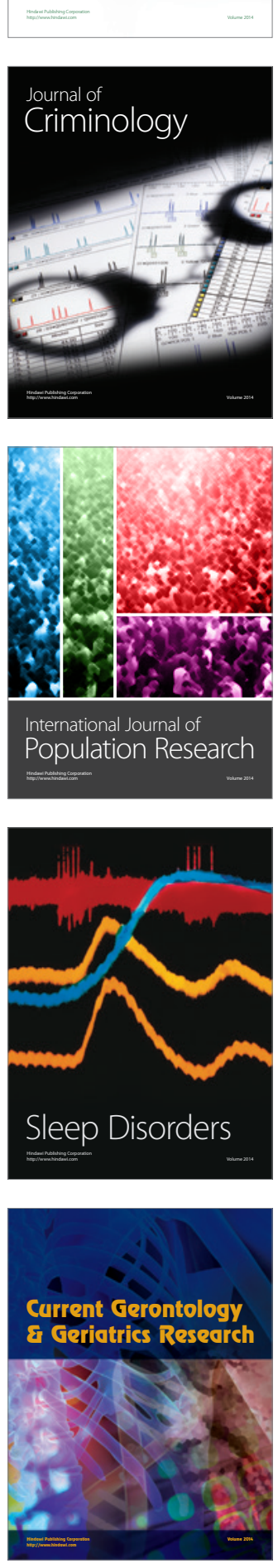
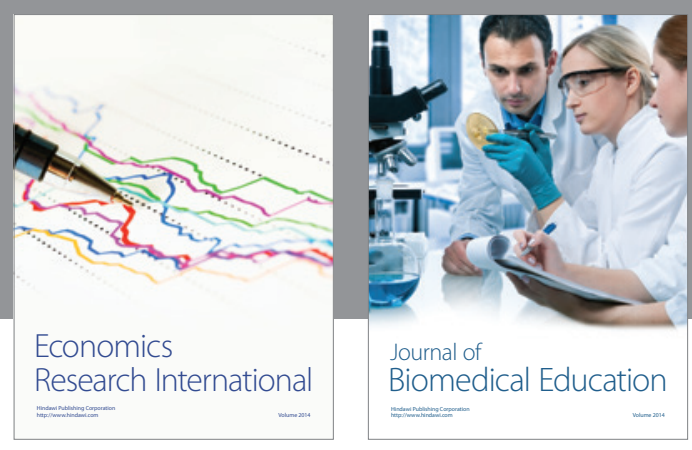

Journal of

Biomedical Education

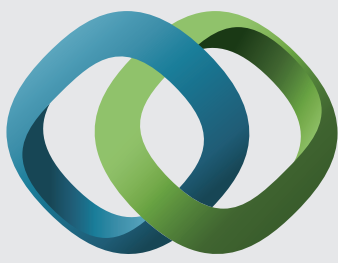

\section{Hindawi}

Submit your manuscripts at

http://www.hindawi.com
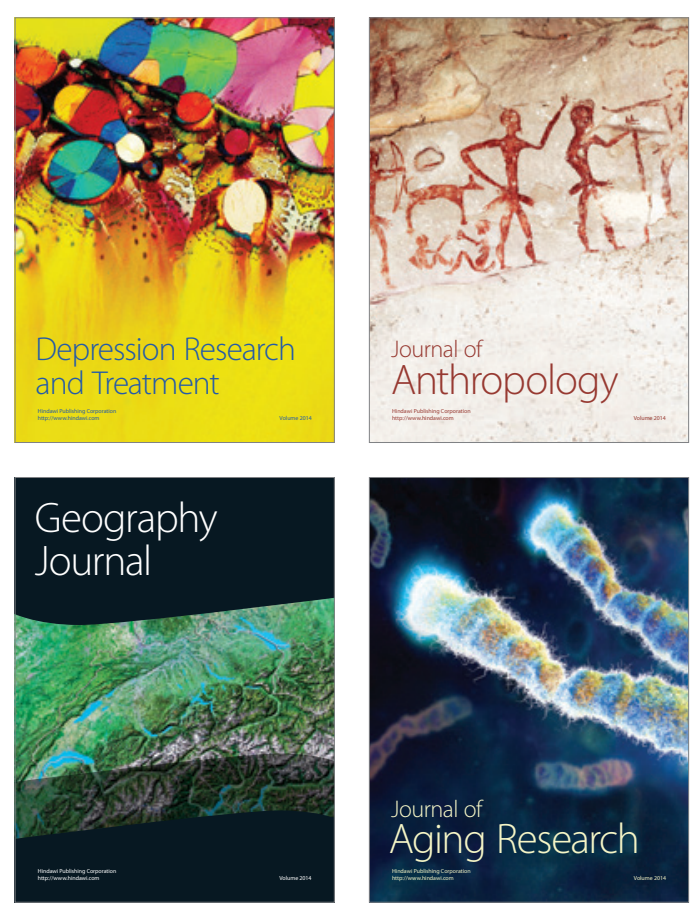

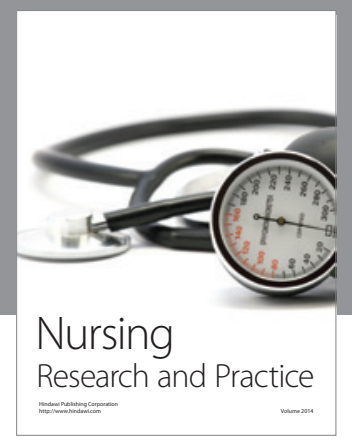

Nursing

Research and Practice

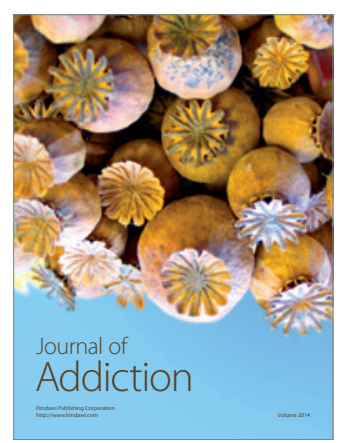

Child Development

Research

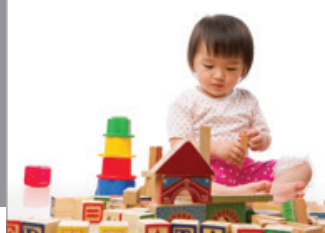

迥
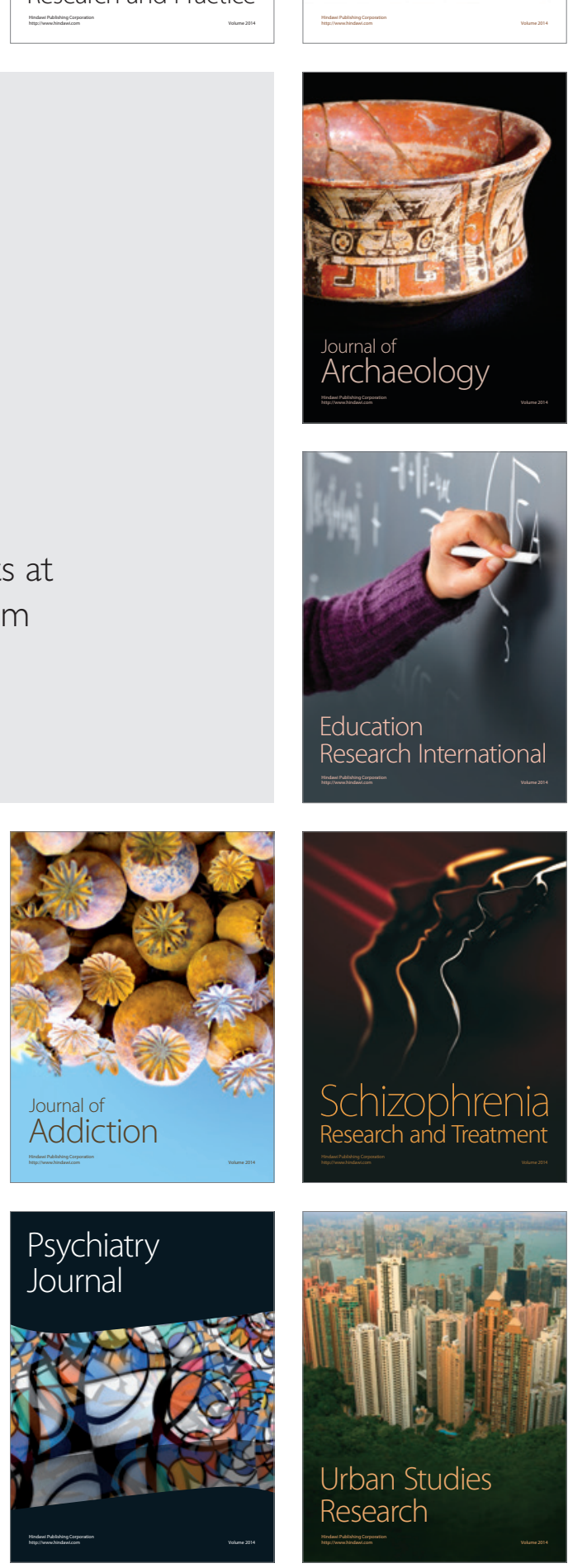